Published in Nature: $21^{\text {st }}$ Feb 2013, vol 494, p349-353

Ecosystem resilience despite large-scale altered hydroclimatic condition

Guillermo E. Ponce Campos ${ }^{1,2}$, M. Susan Moran ${ }^{1}$, Alfredo Huete ${ }^{3}$, Yongguang Zhang ${ }^{1}$, Cynthia Bresloff $^{2}$, Travis E. Huxman ${ }^{4}$, Derek Eamus ${ }^{3}$, David D. Bosch ${ }^{5}$, Anthony R. Buda $^{6}$, Stacey A. Gunter ${ }^{7}$, Tamara Heartsill Scalley ${ }^{8}$, Stanley G. Kitchen ${ }^{9}$, Mitchel P. McClaran $^{10}$, W. Henry McNab ${ }^{11}$, Diane S. Montoya ${ }^{12}$, Jack A. Morgan ${ }^{13}$, Debra P.C. Peters $^{14}$, E. John Sadler ${ }^{15}$, Mark S. Seyfried ${ }^{16}$, Patrick J. Starks ${ }^{17}$

${ }^{1}$ USDA ARS Southwest Watershed Research, Tucson, Arizona 85719, USA

${ }^{2}$ Soil, Water \& Environmental Sciences, University of Arizona, Tucson, Arizona 85721, USA

${ }^{3}$ Plant Functional Biology and Climate Change Cluster, University of Technology Sydney, NSW 2007, Australia

${ }^{4}$ Ecology \& Evolutionary Biology, University of California, Irvine, California, USA and Center for Environmental Biology, University of California, Irvine, California, 92697, USA

${ }^{5}$ USDA ARS Southeast Watershed Research Laboratory, Tifton, Georgia 31793, USA

${ }^{6}$ USDA ARS Pasture Systems \& Watershed Management Research Unit, University Park, Pennsylvania 16802, USA

${ }^{7}$ USDA ARS Southern Plains Range Research Station, Woodward, Oklahoma 73801, USA

${ }^{8}$ USDA FS International Institute of Tropical Forestry, Rio Piedras, 00929, Puerto Rico

${ }^{9}$ USDA FS Rocky Mountain Research Station Shrub Sciences Laboratory, Provo, Utah 84606, USA

${ }^{10}$ School of Natural Resources and the Environment, University of Arizona, Tucson, Arizona 85721, USA

${ }^{11}$ USDA FS NC, Asheville, North Carolina 28806, USA

${ }^{12}$ USDA FS Pacific Southwest Research Station, Arcata, California 95521, USA

${ }^{13}$ USDA ARS Rangeland Research Laboratory, Fort Collins, CO 80526, USA

${ }^{14}$ USDA ARS Jornada Experimental Range and Jornada Basin Long Term Ecological Research Program, New Mexico State University, Las Cruces, New Mexico 88012, USA

${ }^{15}$ USDA ARS Cropping Systems \& Water Quality Research Unit, Columbia, Missouri 65211,USA

${ }^{16}$ USDA ARS Northwest Watershed Research Center, Boise, Idaho 83712, USA

${ }^{17}$ USDA ARS Grazinglands Research Laboratory, El Reno, Oklahoma 73036, USA

Climate change is predicted to increase both drought frequency and duration, and when coupled with substantial warming, will establish a new hydroclimatologic paradigm for many regions ${ }^{1}$. Large-scale, warm droughts have recently occurred in North America, Africa, Europe, Amazonia, and Australia, resulting in major impacts on terrestrial ecosystems, carbon balance, and food security ${ }^{2,3}$. Here we compare the functional response of above-ground net primary production (ANPP) to contrasting hydroclimatic periods in the late-20 ${ }^{\text {th }}$-century (1975-1998) and drier, warmer conditions in the early $21^{\text {st }}$ century (2000-2009) in the Northern and Southern Hemispheres. We found a common ecosystem water-use efficiency (WUE : $_{\mathrm{e}}$ ANPP/evapotranspiration) across biomes ranging from grassland to forest that indicates an intrinsic system sensitivity to water availability across rainfall regimes, regardless of hydroclimatic conditions. We found higher $W_{U E}$ in drier years that increased significantly with drought to a maximum $W U E_{e}\left(W U E_{x}\right)$ across all biomes; and a minimum native state $\left(\mathrm{WUE}_{\mathrm{n}}\right)$ that was common across hydroclimatic periods. This indicates biome-scale resilience to the inter-annual variability associated with the early $21^{\text {st }}$ century drought - e.g., the capacity to tolerate low annual precipitation and to respond to subsequent periods of favorable water balance. These findings provide a conceptual model of ecosystem properties at the decadal scale applicable to the wide-spread altered hydroclimatic conditions that are predicted for later this century. Understanding 
the hydroclimatic threshold that will break down ecosystem resilience and alter WUE $_{x}$ may allow us to predict landsurface consequences as large regions become more arid, starting with water-limited, low-productivity grasslands.

Increased aridity and persistent droughts are projected in the $21^{\text {st }}$ century for most of Africa, southern Europe and the Middle East, most of the Americas, Australia, and Southeast Asia ${ }^{1}$. This is predicted to dramatically change vegetation productivity across ecosystems from grasslands to forests ${ }^{2,4,5}$ with direct impact on societal needs for food security and basic livelihood ${ }^{6}$. However, model predictions of productivity responses can only provide most-likely scenarios of the impact of climate change, and few experiments have focused on how anticipated changes in precipitation might be generalized across terrestrial ecosystems ${ }^{9}$. Long-term measurements of natural variability in field settings, supported by manipulative experiments, are considered the best approach for determining the impact of prolonged drought on vegetation productivity $^{6,7}$.

In field experiments, vegetation productivity is generally measured as the above-ground net primary production (ANPP, or total new organic matter produced above-ground during a specific interval $^{8}$ ) and vegetation response to changes in precipitation is quantified as rain-use efficiency (RUE), defined as the ratio of ANPP to precipitation over a defined season or year ${ }^{9}$. Using this approach, continental-scale patterns of RUE have been reported for extended periods in the late $20^{\text {th }}$ century $^{10}$. Ecosystem water-use efficiency (WUE e ANPP/evapotranspiration ${ }^{11}$ ) provides additional insight into the ecological functioning of the land surface, where evapotranspiration (ET) is calculated as precipitation minus the water lost to surface runoff, recharge to groundwater and changes to soil water storage ${ }^{12}$ (Supplementary Appendix II). Here we compare the functional responses of RUE and $\mathrm{WUE}_{\mathrm{e}}$ to local changes in precipitation to document ecosystem resilience - the capacity to absorb disturbances and retain the same function, feedbacks, and sensitivity ${ }^{13}$ - during altered hydroclimatic conditions ${ }^{14}$.

The objective was to determine how ANPP across biomes responded to altered hydroclimatic conditions forced by the contemporary drought in the Southern and Northern Hemispheres. This study is based on measurementsmade during the period from 2000-2009 at 12 United States Department of Agriculture (USDA) long-term experimental sites in the conterminous United States and Puerto Rico, and 17 similar sites in the Australian continent over a range of precipitation regimes (termed USDA $_{00-09}$ and Australia $01-09$, respectively). To contrast productivity under altered hydroclimatic conditions with precipitation variability in the late $20^{\text {th }}$ century, we compared results from the 2000-2009 period with similar analysis of measurements made during the period from $1975-1998^{10}$. The latter measurements were made primarily at Long-term Ecological Research (LTER) locations, with 14 sites - 12 in North America and 2 in Central and South America - hereafter referred to as the LTER $_{75-98}$ dataset. For a subset of the LTER $_{75-98}$ sites, ANPP measurements were continued during the period from 2000-2009 (termed LTER $_{00-09}$ ) and these were used for further validation of the results (Supplementary Table A1).

85 The warm drought during the early $21^{\text {st }}$ century in the US, Europe and Australia has been recognized as a significant change from the climatological variability of the late $20^{\text {th }}$ century ${ }^{1,15}$. Globally, the 2000-2009 decade ranked as the 10 warmest years of the 130-year (1880-2009) record $^{16}$. Global annual evapotranspiration increased on average by $7.1 \mathrm{~mm} / \mathrm{yr} / \mathrm{decade}$ from 1982-1997, and after that, remained at a plateau through $2008^{17}$, thereby revealing the impact of 90 the drought on this important Earth surface process ${ }^{17}$. In the United States, heat waves in 2005 , 
2006 and 2007 broke all-time records for high maximum and minimum temperatures, and drier than average conditions were reported for over 50\% of the conterminous US in 2000-2002 and 2006-2007 ${ }^{18}$. In Australia, the widespread 6-year drought from 2001 to 2007 was recorded as the most severe in the nation's history ${ }^{19}$. The mean Palmer Drought Severity Index ${ }^{20}$ (PDSI; Supplementary Appendix II) for USDA and Australian sites decreased significantly $(\mathrm{P}<0.002)$ from 1980-1999 to 2000-2009 (USDA) and 2001-2009 (Australia), declining from -0.06 to -0.81 and from 0.09 to -1.34 , respectively, where a reduction in the PDSI indicates an increase in aridity. Furthermore, warm-season temperatures at USDA and Australian sites during the 20002009 and 2001-2009 periods, respectively, were significantly higher $(\mathrm{P}<0.014)$ than 1980-1999 averages, warming by 0.32 and $0.44{ }^{\circ} \mathrm{C}$, respectively.

The Enhanced Vegetation Index $\left(\mathrm{EVI}^{21}\right)$ satellite observations from the Moderate Resolution Imaging Spectroradiometer (MODIS) were integrated annually (termed iEVI) as an empirical proxy for ANPP at USDA ${ }_{00-09}$ and Australia $a_{01-09}$ sites (Supplementary Appendix II). There are multiple publications suggesting that this is a robust approximation of collective plant behavior ${ }^{23}$, and here, we quantified the accuracy of this relation for the biomes, years and precipitation patterns of this study. In situ estimates of ANPP made with conventional field assessment methods $\left(\mathrm{ANPP}_{\mathrm{G}}\right)$ during the period 2000-2009 were compiled for 10 sites across the United States (Supplementary Table A2) and compared with iEVI measurements for the same site and year (Figure 1). A log-log regression resulted in an equation that was used to estimate ANPP from $i E V I$ values $\left(\mathrm{ANPP}_{\mathrm{S}}\right)$, where $\mathrm{ANPP}_{\mathrm{S}}=51.42 \mathrm{x} \mathrm{iEVI}^{1.15}$ resulting in a strong correlation between $\mathrm{ANPP}_{\mathrm{G}}$ and $\mathrm{ANPP}_{\mathrm{S}}$ for this dataset (Figure 1).

\section{Cross-biome $\mathrm{WUE}_{\mathrm{e}}$ during altered hydroclimatic condition}

The response of plant production to precipitation during the contemporary hydroclimatic conditions of prolonged warm drought showed strong agreement with the ANPP/precipitation relations reported during the late $20^{\text {th }}$ century ${ }^{10}$ (Figure 2a). The lowest mean RUE (i.e., slope of the ANPP/precipitation relation) reported for biomes with the highest mean precipitation can be explained largely (though not completely ${ }^{10}$ ) by the rain water that is not available for plant production due to runoff, groundwater recharge and increased soil water storage. Thus, the increase in water available for vegetation production with increasing precipitation is partially consumed by non-biological components of the hydrologic cycle (i.e., runoff and deep drainage). This is particularly true during entrenched drought due to additional storage-refill capacity ${ }^{24}$ of a soil profile that has been depleted of water during prolonged drought. This becomes apparent when production was plotted as a function of evapotranspiration: the mean ecosystem water-use efficiency $\left(\mathrm{WUE}_{\mathrm{m}}\right.$ ) was constant across the entire precipitation gradient (Figure $2 \mathrm{~b}$ ). Further, there were no significant differences among $\mathrm{WUE}_{\mathrm{m}}$ between the three datasets $(P>0.05$ per homogeneity of regression slope test ${ }^{25}$ ). Combined, this indicated that all biomes retained their intrinsic sensitivity to water availability during prolonged, warm drought conditions. This fact suggests that the rules governing how species are organized in terms of their tolerance of hydrological stress are robust despite extended perturbation by low precipitation ${ }^{26}$.

When water limitations at each site were most severe (for the driest years in each multi-year record), a maximum ecosystem WUE ( $\mathrm{WUE}_{\mathrm{x}}$ ) across all biomes was revealed for each of the 3 datasets (Figure $3 \mathrm{a}$ ). The $\mathrm{WUE}_{\mathrm{x}}$ was significantly higher for the Australia ${ }_{01-09}$ sites (PDSI=- 
1.34) than for the LTER $_{75-98}$ and USDA $_{00-09}$ sites (PDSI $~ 0$ and PDSI=-0.81, respectively) ( $P<$ $0.05^{25}$, Figure $3 \mathrm{a}$ inset). This implies a cross-biome sensitivity to prolonged warm drought where ecosystems sustain productivity in the driest years by increasing their $\mathrm{WUE}_{\mathrm{e}}$. It also indicates that in the driest year of the recent prolonged warm drought, water limitations overshadowed the limitations imposed by other resources even at high-productivity sites. The increase in cross-biome $\mathrm{WUE}_{\mathrm{x}}$ with declining PDSI suggests that most biomes were primarily water limited during the driest years of the early $21^{\text {st }}$ century drought.

As a test of ecosystem resilience, a similar comparison was made for the wettest years during mid- to late-drought (2003-2009) and compared to the results for the wettest years during the earlier hydroclimatic conditions from 1975-1998. For the wettest years in both periods, we found a minimum value ( $\mathrm{WUE}_{\mathrm{n}}$ ) that was common to all biomes and similar across both hydroclimatic periods (Figure $3 \mathrm{~b}$ ). The finding that $\mathrm{WUE}_{\mathrm{n}}$ did not vary $\left(P>0.05^{25}\right)$ across different hydroclimatic periods indicates a cross-biome capacity to respond to high annual precipitation, even during periods of warm drought. The decrease from maximum to minimum WUE ranged from $14 \%$ (for the $\mathrm{USDA}_{00-09}$ and $\mathrm{LTER}_{75-98}$ datasets) to $35 \%$ (for the Australia ${ }_{01-}$ 09 dataset) and is hypothesized to occur through additional resource constraints that come into play in wet years, including light and nutrient limitations ${ }^{10,26}$. However, it may also be true that mechanistic relationship between the two time-periods is not consistent, where shifts in contemporary species composition as a result of drought influenced this landscape-scale process.

The ability of plants to increase $\mathrm{WUE}_{\mathrm{x}}$ and retain historic $\mathrm{WUE}_{\mathrm{n}}$ during altered hydroclimatic conditions suggest that the factors controlling these two processes are different with respect to how climate and the vegetation assemblage are changing. During the driest years, there was a cross-biome adjustment in $\mathrm{WUE}_{\mathrm{e}}$ that increased with drought intensity, thus sustaining production at near late- $20^{\text {th }}$-century levels during prolonged drought. In the wettest years, the sites exhibited an ability to absorb the disturbances associated with the early $21^{\text {st }}$ century drought and retained the same sensitivity of ANPP to water availability across both hydroclimatic periods. These different responses to precipitation extremes may be due to changes in vegetation structure and function, and plant-soil feedbacks that are not captured in the integrated analysis of either RUE or WUE . These must be considered in a full assessment of ecosystem vulnerability or resistance to change.

\section{Ecosystem resilience during altered hydroclimatic condition}

In this study, ecosystem resilience was measured as the capacity of ecosystems to absorb disturbances associated with the early $21^{\text {st }}$ century drought and retain late- $20^{\text {th }}$-century sensitivity of ANPP to high annual water availability. Our analyses suggest an intrinsic sensitivity of plant communities to water availability, and a shared capacity to tolerate low annual precipitation but also to respond to high annual precipitation. These findings provide a conceptual model of ecosystem resilience at the decadal scale during the altered hydroclimatic conditions that are predicted for later this century ${ }^{1}$ (Figure 4). During the driest years, the high-productivity sites became water limited to a greater extent resulting in higher $\mathrm{WUE}_{\mathrm{e}}$ similar to that encountered in less productive, more arid ecosystems. It follows that when all ecosystems are primarily water limited, a cross-biome maximum $\mathrm{WUE}_{\mathrm{e}}$ will be reached $\left(\mathrm{WUE}_{\mathrm{x}}\right)$, and that this cross-biome likely has a maximum value cannot be sustained with further reductions in water availability. Further, 
we predict that as cross-biome $\mathrm{WUE}_{\mathrm{e}}$ reaches that maximum $\mathrm{WUE}_{\mathrm{x}}$ value, $\mathrm{WUE}_{\mathrm{n}}$ will approach $\mathrm{WUE}_{\mathrm{x}}$ because production will be limited largely by water supply and less so by nutrients and light (Figure 4).

With continuing warm drought, the single linear ANPP/ET relation that forms the common cross-biome $\mathrm{WUE}_{\mathrm{e}}$ would collapse as biomes endure the significant drought-induced mortality that has been extensively documented over the past decade ${ }^{2,5}$. This loss of resilience associated with dieback would likely occur first for ecosystems that respond most rapidly to precipitation variability (i.e., grasslands ${ }^{27,28}$ ). Thus, the cross-biome ANPP/ET relation would become nonlinear as $\mathrm{WUE}_{\mathrm{x}}$ and $\mathrm{WUE}_{\mathrm{n}}$ approached zero for the most water-limited, low-productivity sites, while $\mathrm{WUE}_{\mathrm{e}}$ values would be less impacted in the high-productivity sites. Subsets of the LTER $_{75-98}(n=4)$, USDA $_{00-09}(n=5)$ and Australia $01-09(n=2)$ datasets limited to grassland sites across a semiarid-to-mesic precipitation gradient were used to corroborate this prediction (Figure 4 inset). During this study period, grassland $\mathrm{WUE}_{\mathrm{x}}$ decreased with increasing aridity (decreasing PDSI) indicating an increasing lack of resilience with prolonged warm drought in these biomes, as predicted. This implies that these systems are closer to a threshold which, when crossed, will result in biome reorganization.

\section{Discussion}

Here we quantified the impact of the early $21^{\text {st }}$ century drought on ecosystem productivity and resilience across many sites on 2 continents. Cross-biome capacities and sensitivities of production were maintained through prolonged warm drought by increases of $\mathrm{WUE}_{\mathrm{e}}$ during the driest years and a resilience during wet years indicated by a common $\mathrm{WUE}_{\mathrm{e}}$ across both hydroclimatic periods. The conclusions are particularly compelling because they are based on measurements across multiple biomes with comparisons of multi-year periods of altered hydroclimatic conditions. These findings were extended to predictions that, if warm drought continues, significant mortality, particularly in low-productivity grasslands that are most sensitive to water availability may threaten ecosystem resilience across biomes given the substantial changes in ecosystem structure. The emergence of these patterns at the spatial and temporal scale at which they were derived requires investigation of the supporting ecohydrological mechanisms that underlie the complex plant-soil couplings. Spatially, this work represents broad cross-biome behavior but does not fully represent the complex site-level response to prolonged warm drought. The site-level mechanisms associated with disease, pests, fire, response lags, species replacement and meristem density in forests ${ }^{2}$ and grasslands ${ }^{4,27,29}$ complicate specific processes maintaining or impacting cross-biome resilience of ecosystem function. Further, there are predictions of a general biogeochemical resetting as increases in carbon dioxide supply affect a multitude of plant and soil processes ${ }^{30}$. Temporally, these predictions of ecosystem resilience were based on behavior at the scale of a decade or longer, including a period of prolonged warm drought. With careful application of this satellite-based metric, it is possible to continue monitoring cross-biome ecosystem resilience at selected crosscontinental sites year-by-year into the future as we develop a greater understanding of the physical and biological mechanisms controlling these patterns.

\section{Methods Summary}


Daily precipitation and temperature were measured at in-situ stations and represented a homogeneous vegetated area of $\sim 2 \times 2 \mathrm{~km}$ and no major disturbances (e.g. fires) during the 20002009 period. Total and mean annual precipitation were computed from daily values over the study period during the hydrologic year (October - September for the U.S. and May-April for Australia). PDSI values at each location were computed using the corresponding precipitation, temperature and soil water holding capacity data. For the Enhanced Vegetation Index (EVI), images (tiles) from the MODIS website were downloaded to extract a measurement every 16days at $250 \mathrm{~m}$ spatial resolution for each site involved. Quality assurance (QA) at the pixel level was applied before window sizes of 9x9 pixels were averaged, including only those pixels that passed the QA control. The resulting time series were smoothed in order to extract more accurate annual integrated EVI values. Estimates of mean annual evapotranspiration were obtained for all the sites by incorporating annual precipitation and percentages of forested and herbaceous cover in a model derived from over 250 catchment-scale measurements from around the world ${ }^{12}$.

232

\section{References}

234

235

236

237

238

239

240

241

242

243

244

245

246

247

248

249

250

251

252

253

254

255

256

257

258

259

260

261

262

263

1. Dai, A. Drought under global warming: a review. Wiley Interdisciplinary Reviews: Climate Change 2, 45-65 (2011).

2. Breshears, D. D. et al. Regional vegetation die-off in response to global-change-type drought. Proc. Natl Acad. Sci. USA 102, $15144-15148$ (2005).

3. Saleska, S. R., Didan, K., Huete, A. R. \& da Rocha, H. R. Amazon forests green-up during 2005 drought. Science 318, 612 (2007).

4. Scott, R. L., Hamerlynck, E. P., Jenerette, G. D., Moran, M. S. \& Barron-Gafford, G. A. Carbon dioxide exchange in a semidesert grassland through drought-induced vegetation change. J. Geophys. Res. 115, 12 PP. (2010).

5. Allen, C. D. et al. A global overview of drought and heat-induced tree mortality reveals emerging climate change risks for forests. Forest Ecol Manag 259, 660-684 (2010).

6. Milly, P. C. D. et al. Stationarity is dead: Whither water management? Science 319, 573 574 (2008).

7. Weltzin, J. F. et al. Assessing the response of terrestrial ecosystems to potential changes in precipitation. BioScience 53, 941-952 (2003).

8. Roxburgh, S. H., Berry, S. L., Buckley, T. N., Barnes, B. \& Roderick, M. L. What is NPP? Inconsistent accounting of respiratory fluxes in the definition of net primary production. Funct Ecol 19, 378-382 (2005).

9. Le Houérou, H. N. Rain use efficiency: a unifying concept in arid-land ecology. J Arid Environ 7, 213 (1984).

10. Huxman, T. E. et al. Convergence across biomes to a common rain-use efficiency. Nature 429, 651-654 (2004).

11. Monson, R. et al. Tree species effects on ecosystem water-use efficiency in a high-elevation, subalpine forest. Oecologia 162, 491-504 (2010).

12. Zhang, L., Dawes, W. R. \& Walker, G. R. Response of mean annual evapotranspiration to vegetation changes at catchment scale. Water Resour. Res. 37, PP. 701-708 (2001).

13. Walker, B., Holling, C. S., Carpenter, S. R. \& Kinzig, A. Resilience, adaptability and transformability in social - ecological systems. Ecol Soc 9, 5 (2004).

14. Holling, C. S. Resilience and stability of ecological systems. Annu Rev Ecol Syst 4, 1-23 (1973). 
15. MacDonald, G. M. Water, climate change, and sustainability in the southwest. Proc. Natl Acad. Sci. USA 107, 21256-21262 (2010).

16. NOAA US climate division data plots. at <http://www.esrl.noaa.gov/psd/data/usclimdivs/>

17. Jung, M. et al. Recent decline in the global land evapotranspiration trend due to limited moisture supply. Nature 467, 951-954 (2010).

18. NDMC U.S. Drought Monitor. (2012).at <http://drought.unl.edu/MonitoringTools/USDroughtMonitor.aspx>

19. BOM, A. Australia's high-quality climate change datasets, Bureau of Meteorology. Australia's High-Quality climate change datasets (2011). at <http://www.bom.gov.au/climate/change/datasets/datasets.shtml>

20. Palmer, W. C. Meteorological drought. Weather Bureau Res. Paper No.45 (1965).

21. Huete, A. et al. Overview of the radiometric and biophysical performance of the MODIS vegetation indices. Remote Sens Environ 83, 195-213 (2002).

22. Running, S. W. et al. A Continuous Satellite-Derived Measure of Global Terrestrial Primary Production. BioScience 54, 547 (2004).

23. Goward, S. N., Tucker, C. J. \& Dye, D. G. North American vegetation patterns observed with the NOAA-7 advanced very high resolution radiometer. Vegetatio 64, 3-14 (1985).

24. Sayama, T., McDonnell, J. J., Dhakal, A. \& Sullivan, K. How much water can a watershed store? Hydrol Process 25, 3899-3908 (2011).

25. Huitema, B. E. The analysis of covariance and alternatives. (Wiley: 1980).

26. Jenerette, G. D., Barron-Gafford, G. A., Guswa, A. J., McDonnell, J. J. \& Villegas, J. C. Organization of complexity in water limited ecohydrology. Ecohydrology (2011).doi:10.1002/eco.217

27. Knapp, A. K. \& Smith, M. D. Variation among biomes in temporal dynamics of aboveground primary production. Science 291, 481-484 (2001).

28. Baldocchi, D. Global change: The grass response. Nature 476, 160-161 (2011).

29. Morgan, J. A. et al. C4 grasses prosper as carbon dioxide eliminates desiccation in warmed semi-arid grassland. Nature 476, 202-205 (2011).

30. Peters, D. P. C., Yao, J., Sala, O. E. \& Anderson, J. P. Directional climate change and potential reversal of desertification in arid and semiarid ecosystems. Glob Change Biol 18, 151-163 (2012).

Full methods and any associated references are available in the online version of the paper at www.nature.com/nature.

Supplementary Information is linked to the online version of the paper at www.nature.com/nature.

Acknowledgements The work was supported in part by the NASA SMAP Science Definition Team under agreement 08-SMAPSDT08-0042 and the Australian Research Council (ARC) Discover Project [DP1115479].

Author Contributions GEPC, MSM and AH conceived the study, assembled the data, and produced the preliminary results. The remaining authors collected and analyzed data, and contributed to the interpretation of results. All authors contributed to writing the paper.

Statistical analyses were performed by GEPC. 
Author information Reprints and permissions information is available at www.nature/com/reprints. The authors declare no competing financial interests. Readers are welcome to comment on the online version of this article at www.nature.com/nature. Correspondence and requests for materials should be addressed to GEPC (geponce@ gmail.com) or MSM (susan.moran@ars.usda.gov).

\section{Figure Captions:}

Figure 1. Relation between ANPP and iEVI. Relation between annual in situ estimates of vegetation production $\left(\mathrm{ANPP}_{\mathrm{G}}\right)$ and the corresponding iEVI derived from MODIS data during the 2000-2009 period for 10 selected sites across multiple biomes (Table A2). The solid line represents the linear regression $\left(\mathrm{R}^{2}=0.82, \mathrm{P}<0.0001\right)$ used to estimate ANPP from iEVI values $\left(\mathrm{ANPP}_{\mathrm{S}}\right)$, where $\mathrm{ANPP}_{\mathrm{S}}=51.42 \times \mathrm{iEVI}^{1.15}$. The inset shows the correlation between estimates of $\mathrm{ANPP}_{\mathrm{S}}$ and $\mathrm{ANPP}_{\mathrm{G}}$ for the 10 sites over multiple years with $\mathrm{R}=0.94$ and root mean squared error $(\mathrm{RMSE})=79 \mathrm{~g} \mathrm{~m}^{-2}$.

Figure 2. Cross-biome sensitivity to precipitation during altered hydroclimatic condition. Relation of plant production to a) precipitation and b) evapotranspiration (ET) across precipitation regimes during the late $20^{\text {th }}$ century $\left(\mathrm{LTER}_{75-98}\right.$, green) and during altered hydroclimatic conditions characterized by prolonged, warm drought (USDA $00-09$ and Australia ${ }_{01-}$ 09 , red), showing significant coefficients of determination in best-fit regressions for each dataset $(P<0.0001)$. Symbols represent the mean values for each site over the multi-year study period. Three LTER sites with in situ estimates of ANPP $_{\mathrm{G}}$ during the 2000-2009 period (black) were included for qualitative validation of results with $\mathrm{ANPP}_{\mathrm{S}}$. The Figure $2 \mathrm{~b}$ inset illustrates differences in mean water-use efficiencies (WUE $\mathrm{W}_{\mathrm{m}}$ the slope of the ANPP/ET relation) across hydroclimatic conditions, where PDSI ranged from $\sim 0$ to -1.34 and columns labeled with the same letter are not significantly different $\left(P>0.05^{25}\right)$.

Figure 3. Ecosystem resilience across biomes and hydroclimatic conditions. a) Maximum $\left(W_{\mathrm{X}}\right)$ and $\left.\mathbf{b}\right)$ minimum ( $\mathrm{WUE}_{\mathrm{n}}$ ) water use efficiency, defined by the slope of the ANPP/evapotranspiration relation in the driest years and wettest years, respectively, based on all

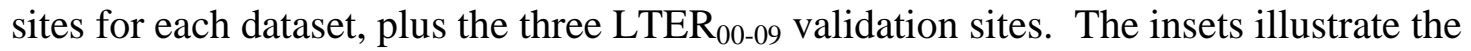
differences in a) $W_{\mathrm{x}}$ and b) WUE $\mathrm{E}_{\mathrm{n}}$ with mean PDSI for the study periods and locations, where columns labeled with the same letter are not significantly different $\left(P>0.05^{25}\right)$ across hydroclimatic conditions.

Figure 4. A conceptual model of ecosystem resilience during altered hydroclimatic condition. a) A summary of $\mathrm{WUE}_{\mathrm{e}}$ results in this study (solid lines), overlain with the predicted behavior of $\mathrm{WUE}_{\mathrm{x}}$ (brown dashed line) and $\mathrm{WUE}_{\mathrm{n}}$ (blue dashed line) along a continuum of sites limited primarily by water and by other resources with an arbitrary distinction made here at ET=700 $\mathrm{mm} \mathrm{yr}^{-1}$ for illustration only (black dashed line). Predictions are based on forecasts of continuing warm drought, resulting in more high-productivity sites that are primarily water limited and an increase in cross-biome maximum $\mathrm{WUE}_{\mathrm{x}}$. When cross-biome $\mathrm{WUE}_{\mathrm{x}}$ reaches a maximum that cannot be sustained with further reduction in water availability, minimum $\mathrm{WUE}_{\mathrm{n}}$ will also reach a maximum, where $\mathrm{WUE}_{\mathrm{n}}$ will approach $\mathrm{WUE}_{\mathrm{x}}$. A non-linear ANPP/ET relation (not shown) will follow as $\mathrm{WUE}_{\mathrm{x}}$ and $\mathrm{WUE}_{\mathrm{n}}$ approach zero for the most water-limited, lowproductivity sites. The inset illustrates the decrease in $\mathrm{WUE}_{\mathrm{x}}$ with PDSI for subsets of the 
$350 \operatorname{LTER}_{75-98}(\mathrm{n}=4), \mathrm{USDA}_{00-09}(\mathrm{n}=5)$ and Australia $01-09(\mathrm{n}=2)$ datasets limited to grassland sites, 351 where columns labeled with the same letter are not significantly different $\left(P>0.05^{25}\right)$. 


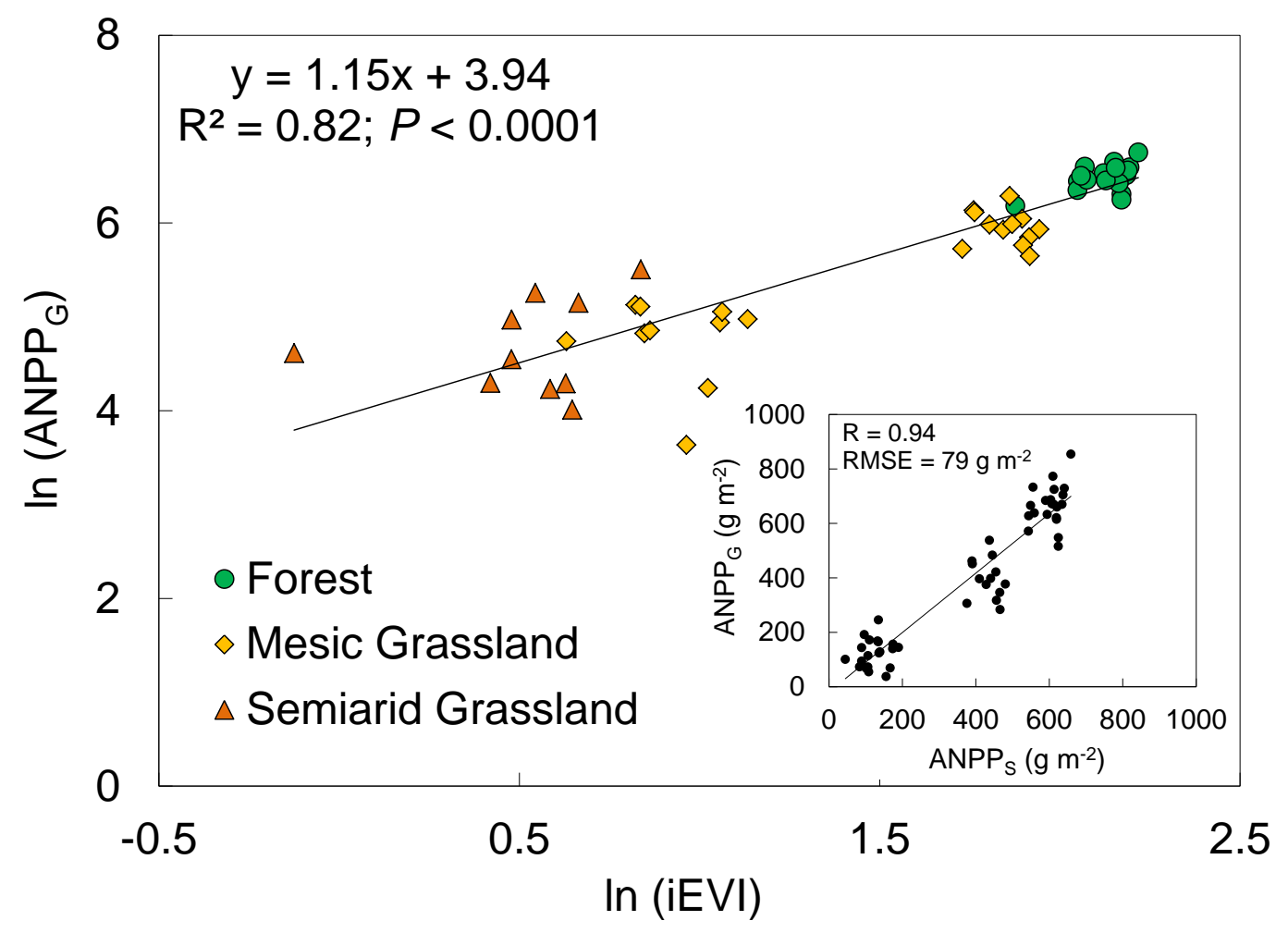

353

$354 \quad$ Figure 1.

355 

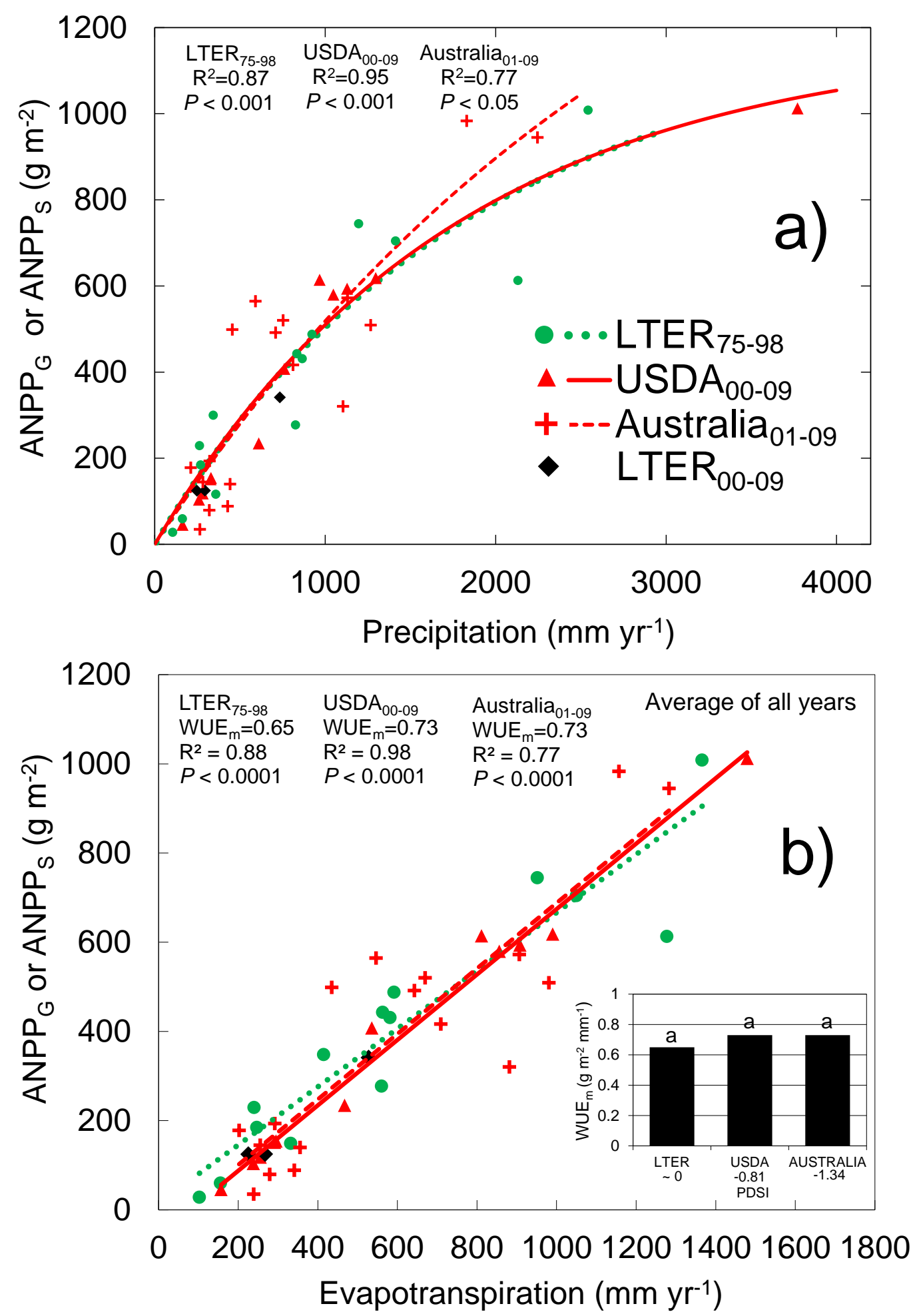

Figure 2. 


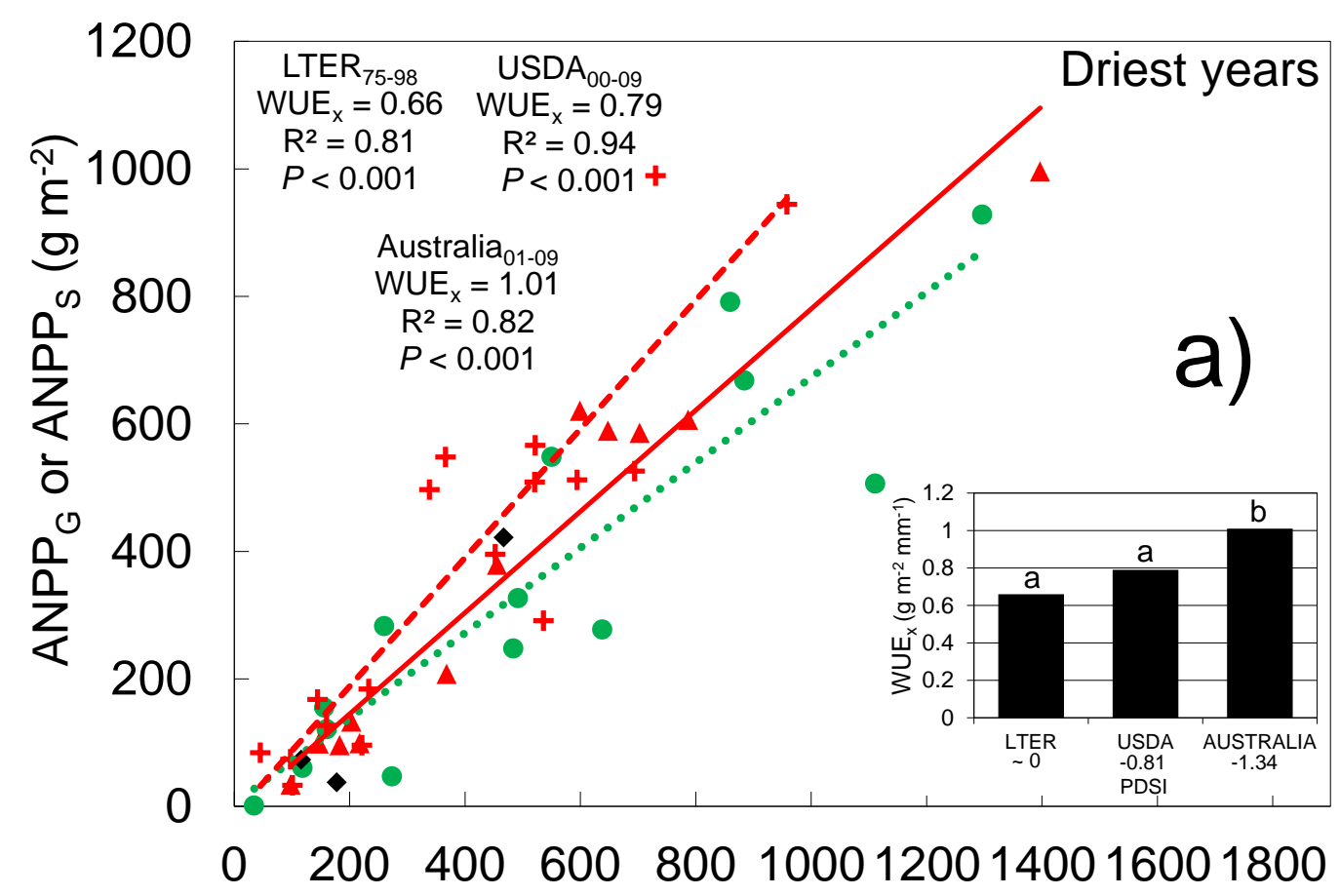

Evapotranspiration $\left(\mathrm{mm} \mathrm{yr}^{-1}\right)$

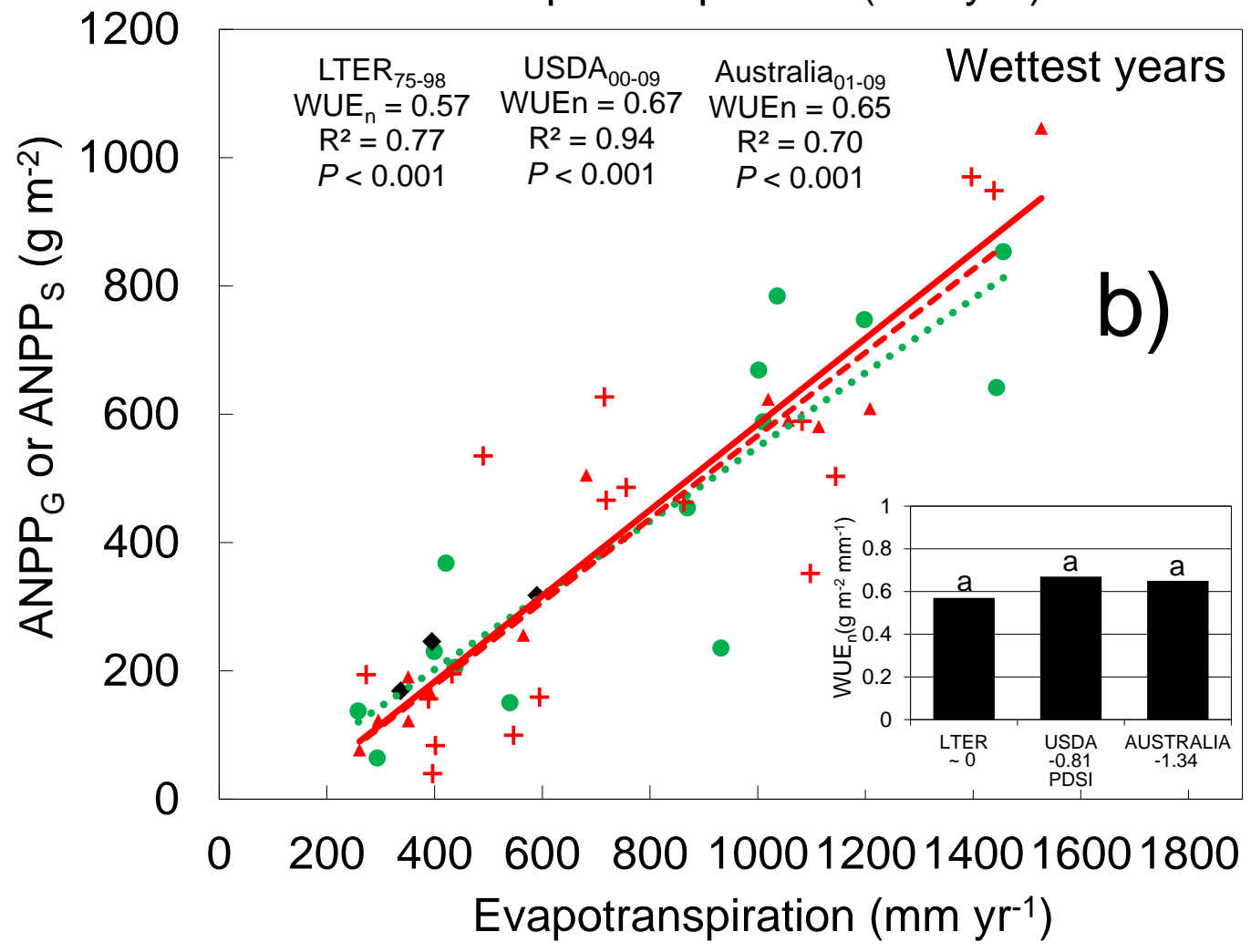

Figure 3. 


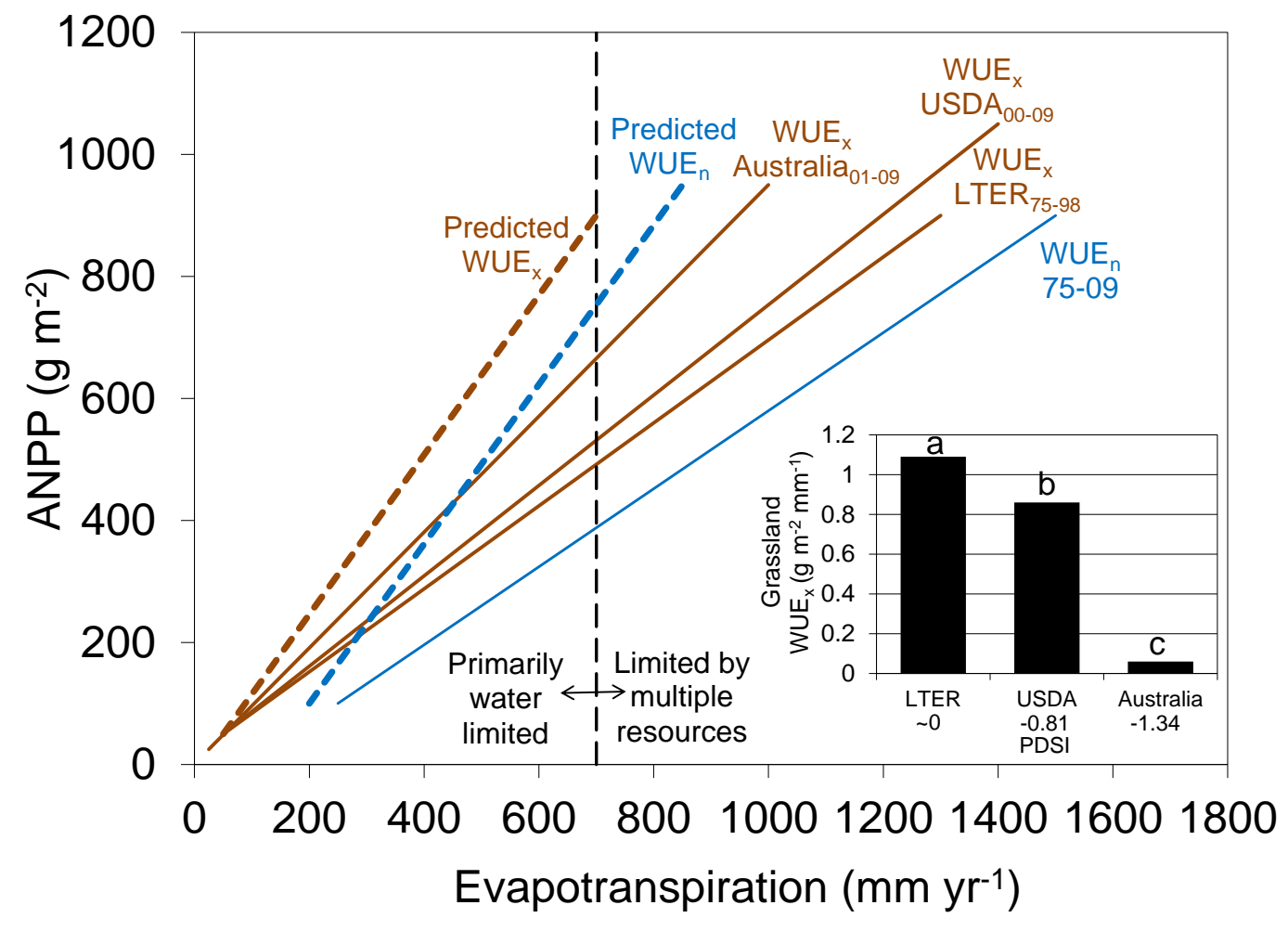

363 Figure 4. 